\title{
Study on the Basic Pattern of Man's Trousers in Southwest Area Based on 3D Scanning Data
}

\author{
Qin LI, Xu LI, Longlin ZHANG* \\ College of Textile \& Garment, Southwest University, Chongqing, China \\ DOI: 10.15221/16.314 http://dx.doi.org/10.15221/16.314
}

\begin{abstract}
The research of clothing structure design is based on the structure of human body, which establishes closer links with the data relations. As the important part of bottoms, the trousers has changed with less area of styles, and its fit and beautiful appearance are particularly important. The aim of this research is to alter $3 \mathrm{D}$ scanning data information, and transmit it into the way of $2 \mathrm{D}$ templates to research the trousers pattern. Through gathering the 3D human data about 500 young men whose age is 18-25 years in Southwest Area, the article extracted 31 key parts of the related data to be turned into 2D pattern, which aim is to reconstruct the basic pattern of male trousers. The first stage is using SPSS software to calculate and analyze the data, and establishing the database of young men lower body model. The second stage is fitting the ergonomics relationship between body shape and pants structure by extracting the point-cloud of key parts, such as crotch curve arc, the cross-section of waist, abdomen and hip, and ham root girth and so on, to reconstruct its model of shape relationship(Fig.1). The last stage is building the basic database of trousers in different regions, size and type, to satisfy the requirement of fit and comfortable with people in the future.
\end{abstract}

Key words: 3D body scanning date; the basic pattern of trousers; trousers construction; the model of human lower body.

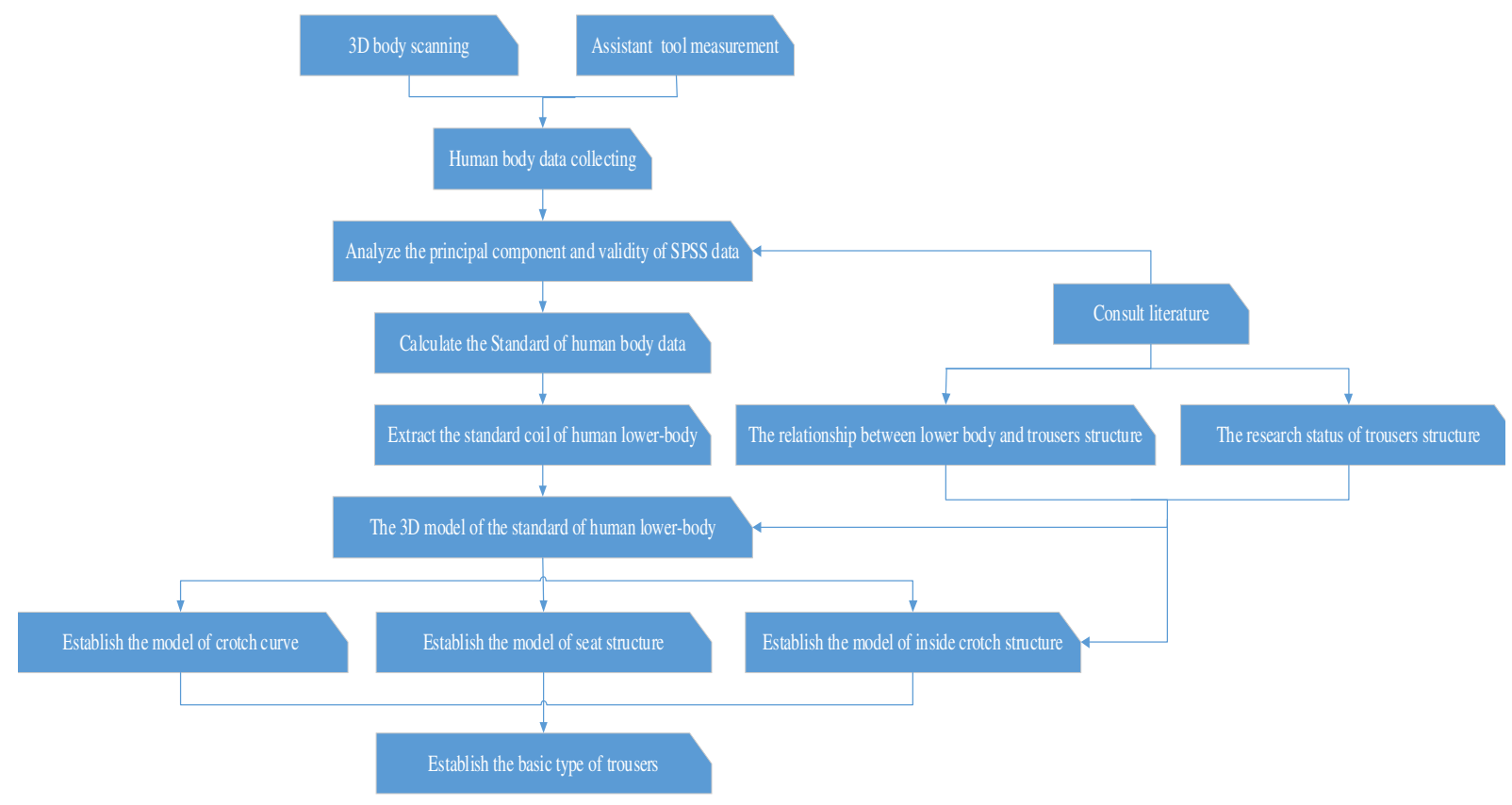

Fig1. The work flow of reconstruction the basic pattern of man's trousers

\section{The research background and the status quo of trousers}

The appearance and comfort of wearing trousers are inextricably linked with structure design. On the base type of trousers, a lot of experts and scholars at home and abroad had put forward the theoretical conception, and there is also a lot of research on it, but is still no mature pants type can be widely used in the industry. Aboard, scholar Ei Chaw Hlaing broke the traditional design method of pants depend on the experience and formula, he transformed the data obtained by the 3D human body scanning to the

*myfashionworks@163.com 
body virtual model. This way is a breakthrough in research methods and approaches on trousers structure pattern through combining the virtual computer model and pattern design. Based on draping technique, the visiting scholar Xuyuan Tao used three-dimensional body scanning data to generate the human body model, and combined it with draping to create the trousers version, which was the further study on the problem of the relationship between the body and trousers structure. In researching for the process that size classification standard effect on different size versions of trousers, according to the difference of waist-buttock and waist-hip ratio, Adriana Petrova and other researchers who came from Cornell University studied the 24 participants ranging from 35 to 55 years old. They divided the subjects into three types such as the thin body, the standard body and the fat body. By extracting the cross section of wearing no loose and loose trousers experiment, they compared and analysed the distribution of the trouser loose quantity.

In the domestic, the researchers used the foreign research ideas of the three-dimensional human body measurement data combined with mathematical statistics analysis method, and they were more and more in-depth study on different types of clothing. But these research are more concentrated in the study of the relationship which is between whole or upper body and clothing structure. In the study of the lower body, there are more concentration in Pants crotch structure design, optimization of the female body, and establishing the pants pattern using mathematical regression model.

In the paper of "Virtual Design of Trousers Pattern Based on 3D Scanning Technology and Related 2D Templates", the author Wei Huanyun obtained the point cloud data using 3D scanner, and completed the processing of raw data and the extraction of tangent curves in GS reverse software. She realized the size adjustment and virtual design of trousers based on the model of human body and clothing, and established the database of trousers basic version design.

The book of "Study on jeans prototype based on body feature of male college students in chinese midwest" written by Zhang zhongqi, he told the readers of using 3D body scanner to get the three dimensional data of male college students in the Midwest, and made the extraction and analysis of lower body characteristic index to set up a fit jeans prototype. With the aid of the draping method, he also made the ergonomics and pants style into the study, which purpose was to provide a technical reference route for the deeper research on pants base type with different size.

This issue intents to use 3D body measurement data to establish the relationship model of the body and the trousers structure. On the one hand, the model will meet the individual requirement of different body types of women; On the other hand, it will provide reference for the mass customization of clothing production.

\section{The establishment of the standard human body model in southwest china}

\subsection{The data collection and processing}

In this article, the 3D cloud points model of 500 men aged 18-25 are obtained by 3D CaMega optical scanner, which is made in Beijing Bowei Hanson. The scanner can classify the collected data to set up the 3D human body model library of young men in Southwest Area. The cloud-points file is influenced by combination of multiple-view point clouds, model own reasons and the environmental factor and so on. We use GS reverse software to eliminate the external isolated points and repair data.

\subsection{The data extraction}

The first stage is to consider the advantages and disadvantages of model automatic segmentation and the characteristic judge technology of human body contour; the second stage is the automatic acquisition the feature points to collect the data of 18 key parts of human body, which includes height, the distance of belt to knee, waist height, crotch height, the length of total leg, the length of the waist to hip, the length of the belt to hip, the length of seat, waist, hip, thigh circumference, knee circumference, ankle girth, the size of hip convex; the last stage is that we divide the coil data into width-to-height and real length. Geomagic Studio measurement tool is used to extract the coil width, and real length is measured by ProE( Fig.2). 

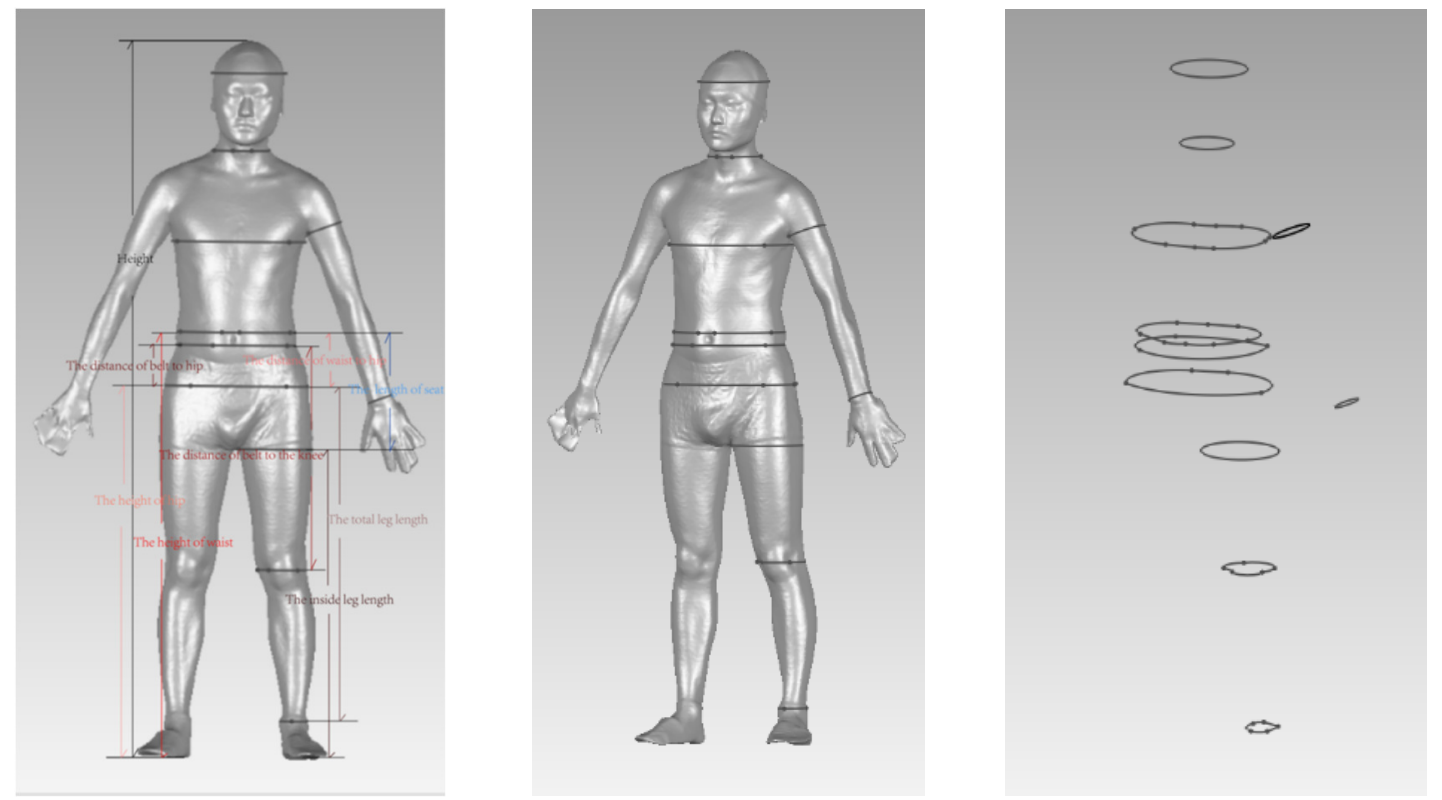

Fig.2 The Sketch of extracting human feature line

\subsection{The modeling of human body standardization}

In the process of using SPSS software to process and analyze the data, the results show that the comparison of the analysis can directly reflect the status quo of the young man's body. In this way, every data value and its height of plane center to ground are weighted, and it can get the 15 key parts coil from waist-down position (Fig.3(a)).

The focus of surface modeling is to form a smooth transition surface by the discrete data point, and make it through or close to these discrete objects. Importing all parts' coil in 3DMAX, after the constraint of the weighted mean value for height, the upper body length, the waist-down position length and the arm length, which is placed on the basis of the weighted mean value of each position.

Because the control grid is mostly the concave and convex points of the human body contour, and the control points of each coil are equivalent. Through the control grid routing connecting all similar grid, we get the full body grid by supplementing cross section line (Fig.3(b)).

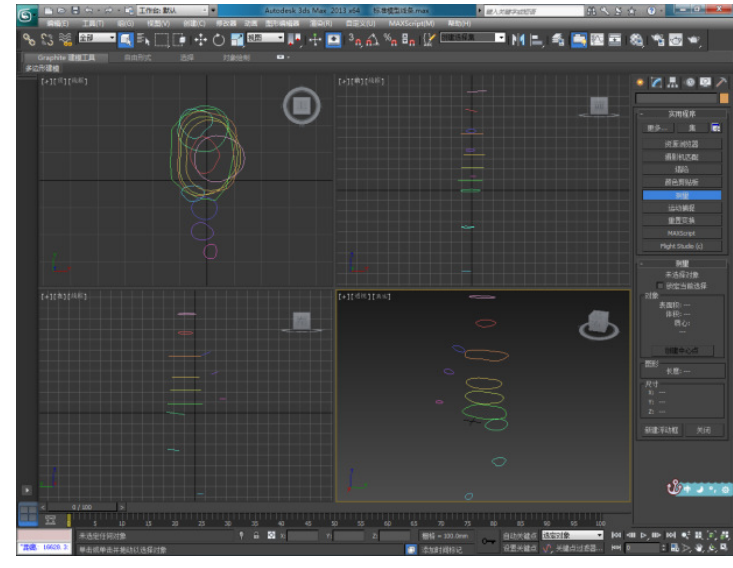

(a)

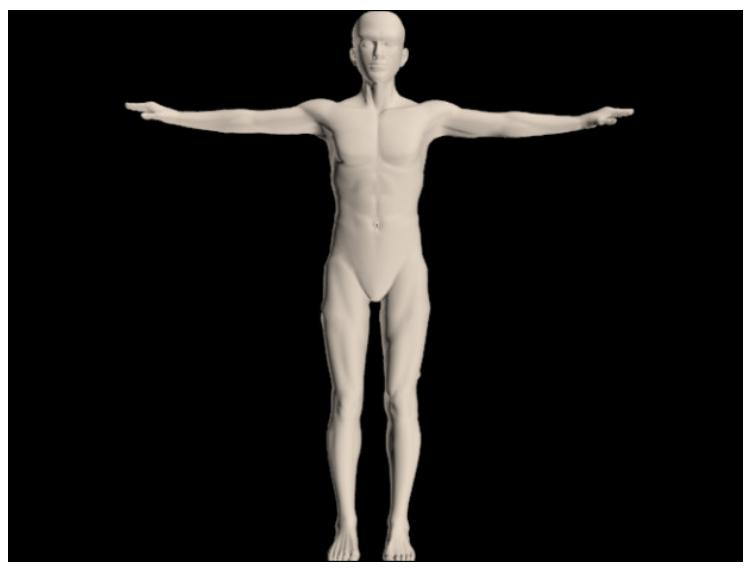

(b)

Fig.3 The establishment of standard human body model in Southwest China 


\section{Study on the prototype of male trousers in Southwest Area based on 3D body data}

\subsection{The establishment of the trouser crotch curve model}

In this research, we study the men's fitting trousers basic model, the experimental results show that the waist-hip ratio is a key data to effect the pants. According to the position of waist, abdomen, hips and body center line, we use the way for creating a graphical cross section to extract the standard body model of the waist line section, and the circumference line section, the hip line section and the crotch curve section in 3dmax software(Fig.4), and export it into *.dxf format. Then, re-import into Autocad, the software can use multi-line segment and measuring tool to process and operate the data.
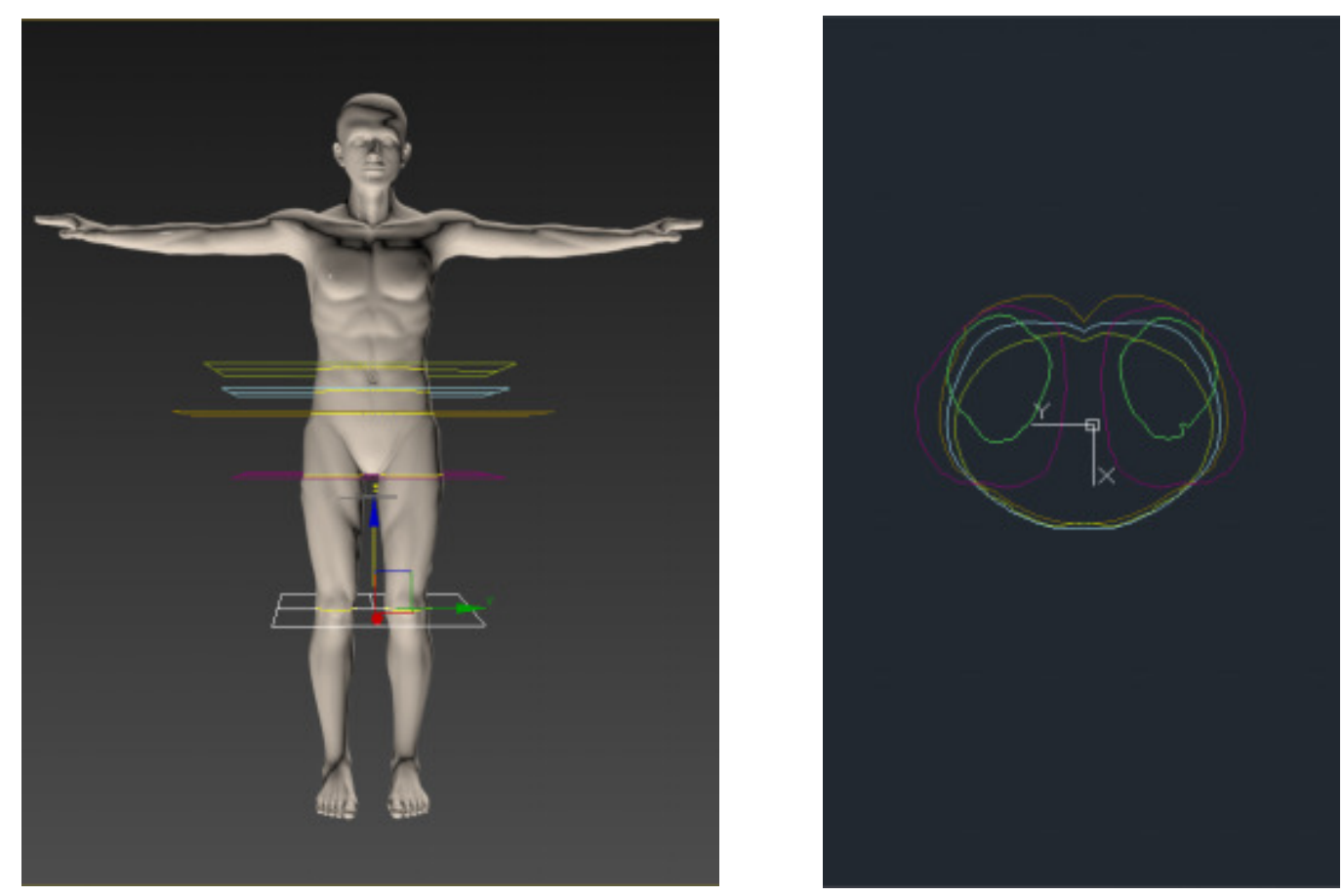

Fig.4 The sketch of extraction the lower body cross section

\subsection{The establishment of seat structure model}

The collected data of the human body database shows the results, the waist-down position is complex and its different from different size. In order to design the waist dart, the researcher use the way of extracting the cross section for waist, abdomen and hip, which can make pants more fit on body by the rational design of waist dart.

\subsubsection{The extraction the cross section of waist, abdomen and buttock}

Firstly, according to the position of waist and abdomen in software 3dmax, we extraction of its cross section to obtain the three sections in the same coordinate system. Secondly, due to the asymmetry of the human body, the result lets the cross section are left-right asymmetry, it need to handle them symmetrical. Thirdly, import the *.dxf format into Autocad, the ideal human coil can be obtained by using the multiple line segment function. Based on the method, we get the right-left side's full symmetry of the waist and abdomen buttocks cross section.

\subsubsection{The establishment the model of waist-hip loose}

The study define the outside surrounding length as hip girth. In order to satisfy the basic requirement loose of body, we put one centimeter loose on the waist line as the trousers waist size, and it also means belt position. Figure 5 shows us that both the outer surrounding section and the waist belt section constitute the model of waist- hip loose. 


\subsubsection{The establishment the loose model of curvature center}

Firstly, setting the center of curvature can provide reference points for the study of the waist dart position and size. Secondly, the cross section of loose model has the left-right symmetry, we make the symmetric axis to let the cross section symmetrical. Thirdly, Fig 6 shows that Assuming the segment between symmetric axis and the outer surrounding is $A$, the segment between symmetric axis and belt position is $B$, and regarded its midpoint as $O$. Then, we draw horizontal line segment through $O$ point, to make it perpendicular to the symmetrical line of section. Finally, take the b/2 length to the right of the points of intersection between segments and belt point, and set the trousers side seam position at intersection between the center of curvature line and belt to obtain point for the center of curvature $O^{\prime}$.

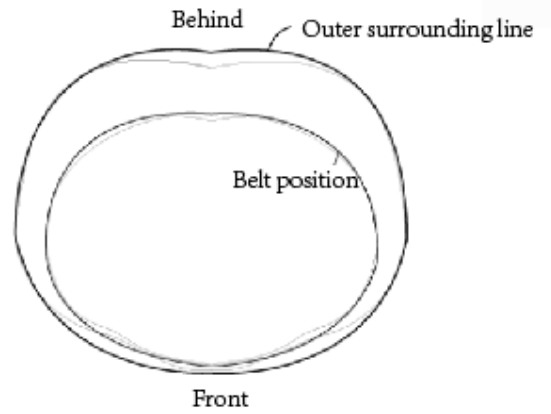

Fig.5 The loose model of lower body

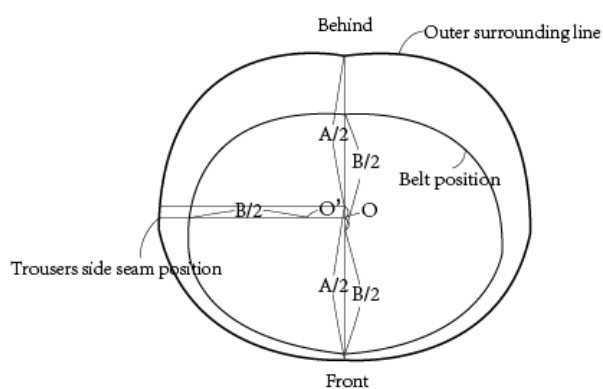

Fig.6 The loose model curvature center

\subsubsection{The establishment of the waist dart}

The waist dart means the difference between belt circumference and outer surrounding, is shown in Table 1.

Table. 1 The human hip dart size

\begin{tabular}{ccc}
\hline Belt surrounding & Outer surrounding & The amount of dart \\
\hline $73 \mathrm{~cm}$ & $92 \mathrm{~cm}$ & $19 \mathrm{~cm}$ \\
\hline
\end{tabular}

The loose model of waist-hip (Fig.7) shows that dart position is closely related to the waist-hip difference and body shape. Fig. 8 tells us that the former central dart is very seldom. With the change of the outer surrounding curvature, the dart gradually increased, until the dart in protruding buttocks point is largest. According to the shape characteristics and the waist distribution, we provided the first dart position D1 in $50^{\circ}$ direction to the left, setting the second dart D2 at side seam. Owing to the back dart is lager, two darts are set there, respectively called D3 and D4.

For distributing the size of dart legitimately, we need to make sure the middle of the dart to be a middle-point dart (Fig.8). To calculate the arc length of outer surrounding as the distance from one middle-point dart to the next and the arc length of the opposite belt position dimension as the distance from the front or back mid-line to the next middle-point dart. Then calculate the difference between them two, the difference is the size of dart.

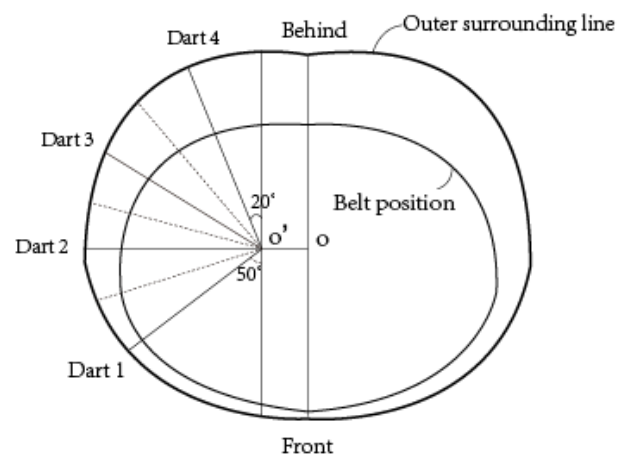

Fig.7 The model of waist-hip loose

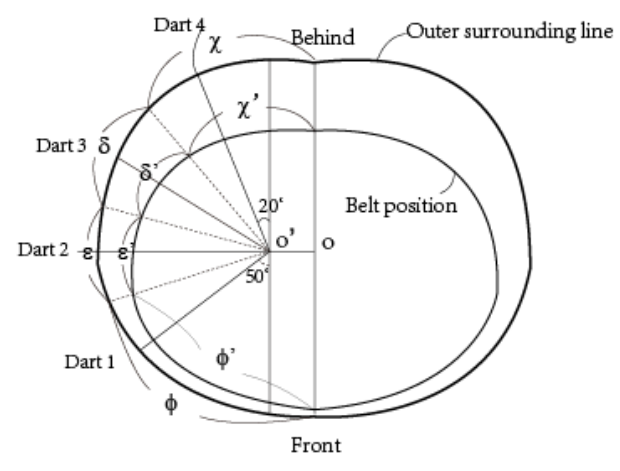

Fig. 8 The distribution situation of waist-hip dart size 
Besides the dart position and size effect on trouser' fit, the dart length can also effect on the waist-to-hip of trouser' fit. The set of dart length can not over the bulging position of waist-down position. The dart length of front piece is about five-seven centimeters not over the abdominal lordosis point. The curvature from waist line to hip ling at the part from side seam to back median. So the dart length of back piece is about eight-ten centimeters and can not over the side bulging position.

\subsection{Drawing the basic structure of trousers}

In summary, we combine the upper crotch pattern and dart pattern to get the pants' basic upper crotch pattern. Let the lowest point of crotch arc line to be point $\mathrm{G}$. We drew a horizontal line to be horizontal crotch line across the point $\mathrm{G}$. The horizontal crotch width is the distance from BH to FH as R. R1 and $\mathrm{R} 2$ stand for front horizontal crotch width and back horizontal crotch width. Let the ratio of them R1 and $\mathrm{R} 2$ to be two, as $\mathrm{R} 1 / \mathrm{R} 2=2$ (Fig.9)

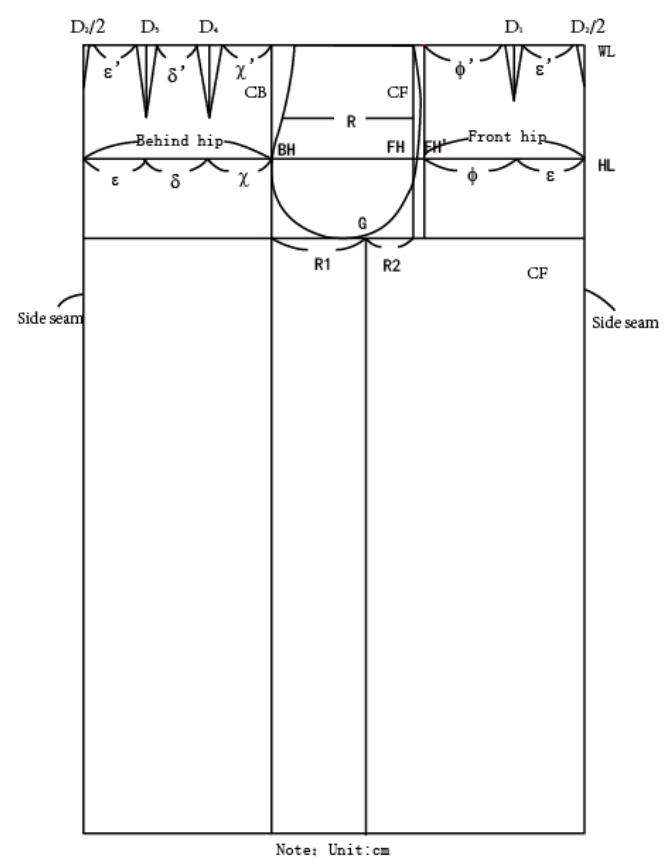

Fig.9 The trouser seat model

\subsection{The establishment model of the lower crotch structure}

The lower crotch structure is the part under crotch, include the crotch line, middle crotch line and bottom line. It can divide pants into two ways, one is fit pants, loose pants and looser pants by loose quantity. One is short type, medium long type and long type. The shape of trouser leg is influenced by crotch width, lower crotch angle and some other structure elements such as crotch size and trouser leg size. Lower crotch design is concerned about horizontal crotch line, middle crotch line and bottom line related to ergonomics. The knee surrounding corresponds to the position of middle crotch, the size of it is concerned about loose. We do trousers shape research according to study the shape of trouser medium crotch.

According to the characteristics of leg, the trousers carry on structure researching and designing profile in the fork of leg width, and the following is straight. Increase the amount of $4 \mathrm{~cm}$ loose on the original knee, the size is the final of leg width. Meanwhile, considering the trousers movement comfort and Shaping the modeling of the leg good effect, the leg width position overall raise up three centimeters, feet mouth design is unchanged, it's the same size with leg width. Table 2 shows the size after Adding amount of loose on trousers.

Table.2 The main parts size of base type trousers (Unit: $\mathrm{cm}$ )

\begin{tabular}{ccccc}
\hline Trousers length & Width length & Crotch line & Middle crotch line & Bottom line \\
\hline 100 & 51 & 54 & 40 & 40 \\
\hline
\end{tabular}




\subsection{The position establishment of leg width dart}

In order to achieve the strong three-dimensional sense of trouser style, the difference size between crotch line and middle crotch line is said to be dart in the leg width. The method is consistent with the way of waist-hip dart researching, it mainly based on reducing dart principles to study the the leg shape on the basis of leg model, dart position and size. Fig.10 demonstrates the two section of crotch line and middle crotch line in 3dmax software. Fig. 11 shows that the dart distribution ratio is determined by the difference of each part corresponding arc length.

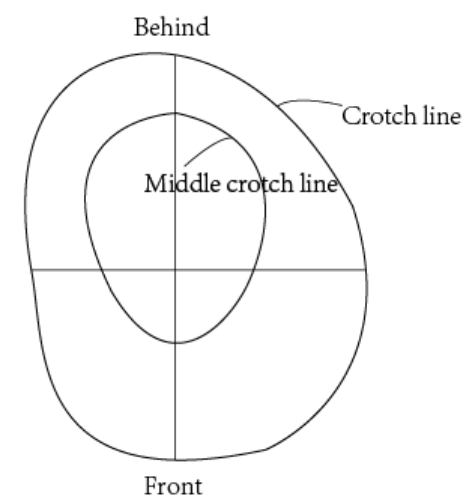

Fig.10 The sectional coincidence diagram of crotch line and middle crotch line

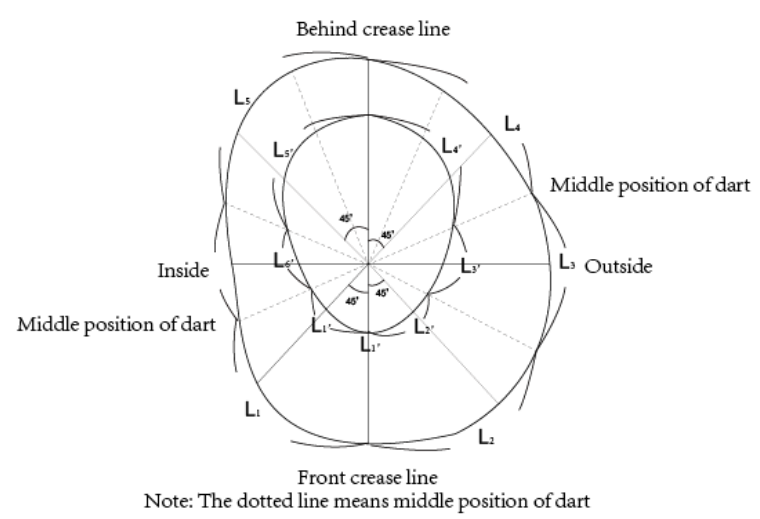

Fig. 11 The sketch map of setting the middle crotch line dart position and distribution dart

\subsection{Drawing the outline structure of trousers}

Fig.12 shows the the sketch map of the men's trousers contour structure basic type is established by mixing together the crotch curve model, the seat model and inside leg model based on $3 \mathrm{~d}$ body data in Southwest area,

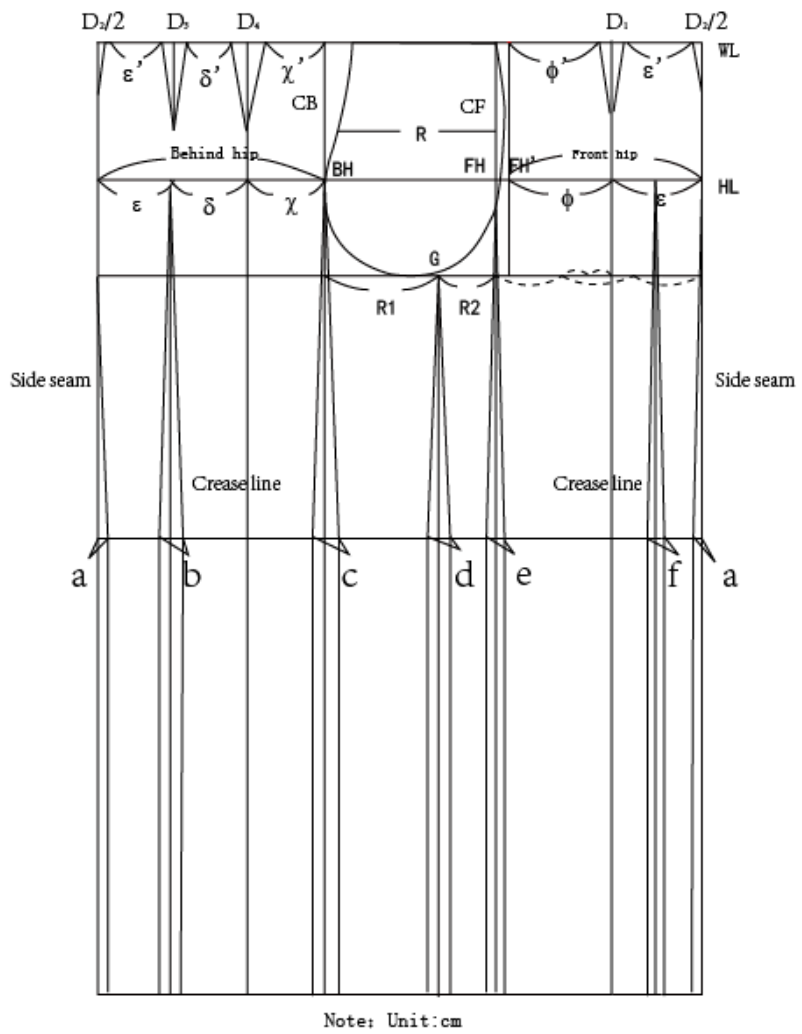

Fig.12 The model of men's trousers contour structure basic type in Southwest area 


\section{Conclusion}

As a new starting point of the research on trousers basic types, we use the way of extracting crotch line to establish the crotch curve model, the seat model and inside leg model. At the same time, we need distribute reasonably the dart of waist-hips and middle crotch to set up the men's trousers basic type sample finally. In this way, we breaks through the simplicity of traditional inference method, and the research satisfy the static beauty and dynamic comfort of trousers.

With a focus on garment ergonomics, the research form precision structure based on data by combining strict logic of 3D data. If the method will be applied to the sales system of digital intelligent fitting, we can achieve the actual garment industry combining technology and art to improve and accelerate the development of the industry structure. Meanwhile, a certain theoretical basis will be established to study the trousers in different regions, size and type.

This research is supported by "Fundamental Research Funds for the Central Universities (XDJK201C100 \& XDJK2014A011)".

\section{Reference:}

[1] GAN Yingjin, CHEN Dongsheng, MENG Shuang. The present situation of non-touch 3D body measurement[J]. Journal of Textile Research. 2005,26(3):145-146.

[2] Ei Chaw Hlaing. Garment prototyping based on scalable virtual female bodies[J]. International Journal of Clothing Science and Technology. 2012, 25(3): 184-197.

[3] Xuyuan Tao. Toward advanced three-dimensional modeling of garment prototype from draping technique[J]. International Journal of Clothing Science and Technology. 2013, 25(4): 266-283.

[4] Adriana Petrova. Body size and shape dependence of ease value for pant's fit[J]. Clothing and Textiles research Journal. 2008, 26(3): 227-252.

[5] ZHANG Qizhong. Study on jeans prototype based on body feature of male college students in chinese midwest[D]. Xi 'an Polytechnic University. 2009: 1-5.

[6] WEI Huanyun, ZHOU Li. Virtual design of trousers pattern based on 3d scanning technology and related 2D templates[J]. China Textile Leader. 2014, 849(8): 64-65.

[7] DING Yulan. The ergonomic[M]. Beijing Institute of Technology. 2002: 71.

[8] ZHI Xiaolei. Research on the trends of the lower part of man's body and the structure of fit-trousers. Donghua University(Shang hai). 2005.

[9] ZHANG Wenbin. The garment structure design[M]. China Textile \& Apparel Press. 2006.

[10] GUO Chaojie. Optimization of trousers' crotch pattern multi-factor for male potbelly[D]. Dalian Polytechnic University. 2015: 26-36.

[11] ZHAO Jingmiao, LI Xiaojiu, WANG Yuxiu. Confirmation of pivotal points for measurement of body digital images based threshold[J]. Journal of Tianjin Polytechnic University. 2004(10):98-101.

[12] YANG Yunchu, CHEN Minzhi. Female body shape parameters analysis based on 3d scan data[J]. Journal of Textile Research. 2009, 30(8): 118-122.

[13] CHEN Minyan, WANG Panxin. Classification of special female figure and trousers pattern design based on the size of waist-abdomen-buttock[J]. Journal of Dong hua University. 2010, 36(2): 129-135.

[14] FANG Jianqiang. Study on the jeans structure design of hip effect [J]. Journal of Dong hua University. 2012: 260-262.

[15] LU Pan. Study on the fitting female trousers based on classification of lower part of human body[D]. Tianjin Polytechnic University. 2012: 2-8.

[16] ZHONG Zeyu, YUAN Guanluo. Body and garment[M]. China Textile \& Apparel Press. 2004.

[17] WU Houlin. Research on pants structural design based on dividers france[J]. Journal of Textile Research. 2010, 31(8): 103-107.

[18] LV, ZHANG Linyun. The spss statistics and applications[M]. China Machine Press. 2009.

[19] Arthur Stewart, Robert Ledingham, Graham Furnace, Alan Nevill. Body size and ability to pass through a restricted space: Observations from 3D Scanning of 210 male UK offshore workers. Applied Ergonomics. 51(2015): 358-362.

[20] Harvey Mrrchell. 3D Body Scanning Technologies. The photogrammetric Record 28(141): 115-116.

[21] Christian Lovato, Umberto Castellani, Carlo Zancanaro, Andrea Giachetti. Automatic labelling of anatomical landmarks on 3D body scans. Graphical Models, 76(2014): 648-657. 